\title{
MEDIATEOLLISUUS LÄHIKUVASSA
}

Vuoden 2018 uutisaiheissa teknologian piilovalta oli Helsingin Sanomien mukaan yksi viidestä isosta uutisaiheesta. Yksityisyyteen liittyen tietoturva ja tietosuoja nousivat keskusteluun isoista tietovuodoista ja Piilaakson mahtifirmojen kuluttajien tietojen väärinkäytöksistä uutisoitaessa (ks. esim. Lassila 2018; Tiainen 2018a; 2018b; 2018c). Teknologian piilovalta tuli näkyviin myös isojen mediateollisuuden toimijoiden, kuten Facebookin ja Googlen, toimintatapoja ja ansaintalogiikkaa ja digitalisaation nurjaa puolta avaavissa tietokirjoissa (Harari 2017; Lanier 2019; Vahvanen 2018). Uutisilla oli vaikutusta. Monet menettivät luottamuksensa mediajätteihin ja jättivät niiden palveluja, mutta monet totesivat myös, etteivät enää tule toimeen ilman niitä (Halminen 2018).

Ajatus teknologian piilovallasta nostaa helposti mieleen dystooppisia, jopa orwellilaisia mielikuvia, eikä täysin perusteetta. Varmasti monet ovat kokeneet, kuinka ovat ensin etsineet vaikkapa älypuhelimien hintoja verkossa, jonka jälkeen seuraavaksi somesyötteeseen alkaa ilmestyä niitä myyvien kauppojen mainoksia. Tällöin tilanteessa on mukana jo useampi toimija: käytetty laite, internet, algoritmeja luovat ohjelmistot, se laite, jota ihminen on hankkimassa, sekä niitä valmistavat ja myyvät yritykset. Mahdollisesti somesyötteeseen alkaa ilmestyä myös mediasisältöjä, kuten elokuvia tai pelejä, markkinoivia viestejä. Nämä kaikki ovat mediateollisuuden (media industry) toimijoita ja tuotteita. Mediateollisuus on monialainen kokonaisuus, johon kuuluvat niin tuotanto, jakelu, markkinointi sisällöt, teknologia, mediat sekä tietysti yleisöt - kuluttajat. Nämä osat ovat eri tavoin verkottuneet ja kanssakäymisessä keskenään.

Mediateollisuuden tutkimus on osaltaan median tuotannon ja toimintalogiikan näkyviin tuomista. Mediateollisuus tutkimusalana syntyi tarpeesta analysoida digitalisoinnin aiheuttamaa mediamuutosta. Digitalisaatio muovasi 2000-luvulle tultaessa merkittävästi mediateollisuuden liiketoimintamalleja, jakelustrategioita, markkinointikeinoja ja tuotanto- ja työskentelytapoja. Median taloudellisesta ja teknologisesta konvergenssista puhuttaessa haluttiin myös tutkimusalojen konvergenssia: Douglas Kellner nosti esiin tarpeen yhdistää historia, yhteiskuntatieteet, poliittinen taloustiede ja media- ja kulttuurintutkimus, jotta voitaisiin kunnolla kontekstualisoida ja analysoida kriittisesti mediateollisuuden tuotteita (Kellner 2009, 95-96). 
Vuonna 2009 ilmestyivät tutkimusalaa määrittelevät teokset Media Industries: History, Theory, and Method ja Production Studies: Cultural Studies of the Media Industries sekä artikkeli "Critical Media Industry Studies: A Research Approach". Vaikka mediateollisuutta määriteltiin uutena tutkimusalana ja sen alle koottiin edeltävien vuosien tutkimuksia mediayhtiöiden konglomeraatiosta, globalisaatiosta ja digitalisoitumisesta, haluttiin mediateollisuus käsitteenä kytkeä Frankfurtin koulukunnan kulttuuriteollisuuden käsitteeseen. Theodor Adornon ja Max Horkheimerin essee The Culture Industry: Enlightenment as Mass Deception (1944) on ollut vaikutuksellinen mediateollisuudesta käytettyihin käsitteisiin ja puhetapoihin. Tuolloin Adorno ja Horkheimer halusivat kulttuuriteollisuus-käsitteellä painottaa massatuotetun kulttuurin teollista luonnetta ja sitä ohjanneita kaupallisia imperatiiveja.

Mediateollisuus on muuttunut vuosikymmenen aikana, kun digitalisaation prosessiin on 2010-luvulla kytkeytynyt yhä uusia ilmiöitä. Suuret teknologiayritykset, kuten Amazon, Apple, Facebook, Google ja Netflix ovat nousseet haastamaan perinteisiä mediajättejä, kuten Time Warner, Disney ja NewsCorp/Fox. Uudet syntyjään digitaaliset mediamuodot, kuten nettisarjat ja podcastit, ovat löytäneet yleisönsä ja vallanneet sijaa vanhoilta medioilta. Fyysisten mediamuotojen - erityisesti DVD:n - myynti on tippunut suoratoistopalvelujen myötä.

Mediateollisuuden tutkimus on vuosikymmenen aikana vakiintunut jo tieteenalaksi. Tieteenalan määrittelystä ja makrotason keskusteluista on siirrytty mikrotasolle. Jennifer Holtin ja Alisa Perrenin mukaan mediateollisuuden tutkimuksen alalla on luovasti jäljitetty historiallisia jatkumoita, kehitetty teoreettisia kehyksiä ja innovatiivisia metodologisia ratkaisuja esimerkiksi luovista työläisistä ja mediatyöstä, digitaalisesta jakelusta, alustoista ja algoritmikulttuurista sekä infrastruktuurista. Kaikkia näitä alueita yhdistävät laajemmin kysymykset pääsystä (access), yleisöistä, verkostoista ja lopulta pyrkimys uudenlaiseen tieteelliseen aktivismiin viime vuosina. Aiempi optimismi digitaalisen jakelun ja osallistumisen kulttuurin mahdollisuuksista on osaltaan vaihtunut nykyisen digitaalisen mediasysteemin kovien kaupallisten arvojen tunnistamiseen. (Holt \& Perren 2019, 34-38.) Viimeaikaiset väärinkäytökset ovat herättäneet tarpeen mediateollisuuden toimijoiden ja toimintatapojen avaamiseen kuluttajien tietoisuuden lisäämiseksi. Mediateollisuuden tutkimuksella on mahdollisuus osallistua aktiivisesti tämän tietoisuuden kasvattamiseen ja keskusteluun median toimintatavoista.

Suomessa mediateollisuuden tutkimus ei ole vuosikymmenen aikana vakiintunut omaksi tieteenalakseen, mutta sitä on määritelty tutkimusalaksi esimerkiksi televisiotutkimuksen parissa (ks. esim. Kannisto 2018; Keinonen 2018). Mediateollisuuden näkökulmaa on hyödynnetty mediahistorian tutkimukseen, ei vain viime vuosien nopeiden muutosten tarkastelussa. Myös tässä Lähikuvan Mediateollisuus-teemanumerossa tutkimusartikkelit tarkastelevat mediateollisuutta historiallisten esimerkkien kautta.

Viimeaikaisen digitalisaatiokehityksen ohella onkin yhtä lailla tärkeää tarkastella historiallisesti mediateollisuuden valtasuhteita ja toimintalogiikoita. Mediateollisuuden yhtiörakenteissa ovat eri aikoina vaihdelleet vapaa yhdentyminen ja lakien sääntelemä eriyttäminen. Esimerkiksi Hollywoodin elokuvateollisuudessa 1920-luvulla kukoistanut isojen studioiden vertikaalinen yhdentyminen purettiin, kun sääntelyä alettiin luoda 1930-luvulla laman jälkeen ja jatkettiin 1970-luvulle asti. Eriyttäminen alkoi purkautua ja mediateollisuuden fuusiot yleistyivät uudestaan 1980-1990-luvun aikana kansainvälisesti. Erityistä 1980-luvulta alkaneessa yhdentymisessä on ollut 
sen laajentuminen eri aloille synergian nimissä, mikä on keskittänyt valtaa muutaman jättimäisen mediaimperiumin taakse.

Numeron avaavassa tutkimusartikkelissa Maiju Kannisto ja Paavo Oinonen tarkastelevat varhaista videohistoriaa mediateollisena kamppailuna. Mediateollisuuden eri toimijat osallistuivat keskusteluun teknologisesta uutuudesta, kasettitelevisiosta, 1970-luvun alussa. Keskustelu ei suinkaan rajoittunut ainoastaan teknologisiin kysymyksiin, vaan aikakaudelle tyypillisesti väittelyn keskiössä oli kysymys siitä, kuka saa tuottaa sisältöä kasettitelevisioon, kaupalliset toimijat vai valtio. Keskustelu polarisoitui poliittisen oikeiston ja vasemmiston välille. Uudesta teknologiasta keskusteltaessa mediateollisuuden toimijat rakensivat kasettitelevisiolle toimijamaailman, vision teknologian mahdollisuuksista ja käyttötavoista. Artikkeli osoittaa, että teknologioiden varhaisvaiheiden tutkimus antaa ymmärrystä siitä, miten mediateolliset ratkaisut ovat seurausta monien eri toimijoiden ja ideoiden kamppailusta.

Myös numeron toisessa tutkimusartikkelissa tutkitaan mediateollisuuden alan varhaishistoriaa. Tero Pasasen ja Jaakko Suomisen artikkeli käsittelee sittemmin suurmenestykseksi nousseen suomalaisen digitaalisen peliteollisuuden pioneerivaihetta 1980-luvun puolivälissä. Amer-yhtymän tytäryhtiö Amersoft oli ensimmäinen suomalainen yritys, joka pyrki laajamittaisesti julkaisemaan kotimaisia tietokonepelejä. Kirjoittajat analysoivat eri osa-alueita, jotka vaikuttivat toiminnan jäämiseen tuolloin kaupallisesti kannattamattomaksi. Pasasen ja Suomisen mukaan Amersoftilta puuttui johdonmukainen liikestrategia, ohjelmistopiratismi oli tuolloin laajaa, ulkomaisilla peleillä oli vankka asema markkinoilla, Suomen markkinat itsessään olivat pienet ja yhtiön pelit kärsivät laatupuutteista. Artikkeli syventää suomalaista pelihistorian tutkimusta ja tuntemusta ja tuo näkyviin pioneeritutkimuksen haasteen: arkistomateriaalia ei löytynyt vain lyhyen aikaa toimineesta Amersoftista, vaan tutkimusmateriaali koostuu työntekijöiden haastatteluista ja oheisjulkaisusta, kuten henkilöstölehdistä, uutisista, arvosteluista ja mainoksista. Mediateollisuuden epäonnistuneita hankkeita on kiinnostava mutta hankala tutkia, koska yhtiöiden arvottomana pidettyä materiaalia ei ole arkistoitu.

Kolmas tutkimusartikkeli siirtyy mediateollisuuden historiallisesta tarkastelusta 2000-luvulle ja aina tähän päivään asti. Pauliina Tuomi analysoi ohjelmistoa kehittämänsä uuden termin - provokatiivinen televisiotuotanto - kautta. Provokatiivisella televisiotuotannolla Tuomi tarkoittaa tv-sisältöjä, jotka ovat jollakin tapaa yleisiä arvoja, normeja ja jopa moraalikäsityksiä ravistelevia. Tuomi löytää laajasta ohjelma-aineistostaan viisi tendenssiä, joilla ohjelmat pyrkivät tuottamaan eroa katsojan ja hänen normiensa sekä ohjelmissa esiintyvien ihmisten ja heidän normiensa välille, ja vetoamaan siten kauhistumisen, närkästymisen ja mahdollisesti myös ironisen huvittumisen reaktioihin. Näitä tendenssejä ovat poikkeavuus/toiseus, huonous/eripura, makaaberi, irstaus/hävyttömyys ja ravistelu/rajojen rikkominen. Tunteiden herättäminen näiden tendenssien avulla on Tuomen tulkinnan mukaan strategia, johon mediayhtiöt ovat turvautuneet kiristyvässä kilpailussa. Provokatiivista tv-tuotantoa kuvaakin nopea ja halpa tuotannon sisältö, jonka pitää pystyä pitämään katsojat kanavalla. Voi pohtia, miksi juuri negatiiviset tunteet imevät katsojan niin helposti mukaansa.

Katsausartikkeleiden tapaustutkimukset valottavat monipuolisesti niin mediatuotteiden tekoa, jakelua kuin markkinointia. Maarit Kalmakurki tarkastelee 3D-pukusuunnittelua 2000-luvun Shrek-animaatioelokuvissa. Digitaalisuus ja kolmiulotteisuus merkitsivät täysin uutta suunnittelutapaa, jossa ammattimaisen pukusuunnittelijan työpanos hyödytti elokuvaa taiteellisesti, 
teknisesti ja taloudellisesti. Toisaalta samalla kun uudet teknologiat ovat mahdollistaneet monipuolisen ilmaisun esimerkiksi materiaalien realismin välittämisenä, ne ovat myös tuoneet pukusuunnitteluun rajoituksia, esimerkiksi hahmon puvun muodon muuttamiseen elokuvassa. Kalmakurki nostaa esiin kiinnostavan ristiriidan: teknologian kehityksen myötä pian on mahdollista toteuttaa melkein mitä vaan, mutta useimmiten huipputeknologiaa käytetään vaatteiden visuaalisuudessa niiden tarkemman realismin kuvaamiseen. Realismin sijaan voisi keksiä uudenlaisia visuaalisia keinoja ilmaista vaatetta, joka tuottaisi katsojalle fantasiamaisia elämyksiä.

Eija Niskanen tarkastelee japanilaista muumien animehistoriaa 1960-luvulta tähän päivään ja pohtii eri versioiden merkityksiä muumimielikuviin niin Japanissa kuin Suomessakin. Niskanen esittelee myös usein unohdettua Muumi-animaatiosarjaa 1960-1970-lukujen taitteesta 1990-luvun Suomessakin esitetyn sarjan rinnalla. Hän nostaa esiin muumien merkityksen niin japanilaisen animaation tekijöiden uralle kuin laajemmin japanilaiselle kulttuurille. Muumit ovat yksi esimerkki animeteollisuuden kansainvälisistä transmediaalisista synergioista.

Rami Mähkän aiheena on Tuukka Temosen Valmentaja-elokuvan (2018) markkinointi. Mähkän mukaan tekijät ymmärsivät elokuvan päähenkilön, bisnesvalmentaja Jari Sarasvuon, herättävän voimakkaita reaktioita puolesta ja vastaan. Tämän vuoksi markkinoinnin tyylilajiksi valittiin ironinen "närkästyttäminen", johon elokuvan mainoslause, "tule ja närkästy", suoraan viittasi. Ärsyttäminen mainosstrategiana ei kuitenkaan toiminut, ja elokuva floppasi. Mähkän artikkeli osoittaa, että markkinointistrategiat eivät aina onnistu, vaikka markkinoijat, elokuvantekijät ja jopa mediakommentoijat pitäisivät niitä hyvinä - jos elokuvan aihe ei yksinkertaisesti kiinnosta yleisöä, harva lähtee elokuviin ärsyyntymään.

Ansiokkaiden artikkelien kautta tämä Lähikuvan mediateollisuus-numero on osaltaan määrittelemässä ja vakiinnuttamassa mediateollisuuden tutkimusalaa Suomeen. Teollisuuden näkökulmaa korostaessamme on kuitenkin tärkeää huomata, että mediateollisuus eroaa muista teollisuudenaloista merkittävästi. Media ei tuota vain tuotteita kulutettavaksi, vaan on myös tärkeä tiedon lähde, viihdyke ja kansalaisia yhdistävä väline, jolla on huomattava merkitys demokraattisessa yhteiskunnassamme.

Turussa, tammikuussa 2019

Maiju Kannisto ja Rami Mähkä

\section{Lähteet}

Halminen, Laura (2018) "Some ärsyttää yhä useampaa". Helsingin Sanomat 20.12.2018.

Harari, Yuval Noah (2017) Homo Deus. Huomisen lyhyt historia. Helsinki: Bazar.

Havens, Timothy \& Lotz, Amanda D. \& Tinic, Serra (2009) "Critical Media Industry Studies: A Research Approach". Communication, Culture \& Critique 2(2): 234-253.

Holt, Jennifer \& Perren, Alisa (toim.) (2009) Media Industries: History, Theory, and Method. Chichester: Wiley - Blackwell.

Holt, Jennifer \& Perren, Alisa (2019) "Media Industries: A Decade in Review". Teoksessa Mark Deuze \& Mirjam Prenger (toim.) Making Media: Production, Practices, and Professions. Amsterdam: Amsterdam University Press, 31-43. 
Kannisto, Maiju (2018) Ohjelmayhtiöstä "merkintekijäksi": MTV ja kaupallisen television tuotantokulttuurin muutos Suomessa 1980-luvulta 2000-luvulle. Turun yliopiston julkaisuja. Sarja C, Scripta lingua Fennica edita. Turku: Turun yliopisto.

Keinonen, Heidi (2018) Televisioformaatti ja kulttuurinen neuvottelu. Nykykulttuurin tutkimuskeskuksen julkaisuja 123. Jyväskylä: Jyväskylän yliopisto.

Kellner, Douglas (2009) "Media Industries, Political Economy, and Media/ Cultural Studies: An Articulation". Teoksessa Jennifer Holt \& Alisa Perren (toim.) Media Industries. History, Theory, and Method. Chichester: Wiley - Blackwell, 95-107.

Lanier, Jaron (2019) 10 syytä tuhota kaikki sometilit nyt. Helsinki: S\&S.

Lassila, Anni (2018) "Facebook jäi kiinni yksityisviestien vuotamisesta". Helsingin Sanomat 20.12.2018.

Mayer, Vicki; Banks, Miranda \& Caldwell, John Thornton (toim.) (2009) Production Studies: Cultural Studies of the Media Industries. New York: Routledge.

Tiainen, Antti (2018a) "Teknologian piilovalta paljastui karusti". Helsingin Sanomat 9.12.2018.

Tiainen, Antti (2018b) "Internetistä tuli painajainen". Helsingin Sanomat 15.12.2018.

Tiainen, Antti (2018c) "Demokratia on uhattuna, jos tekoälyjärjestelmistä ei tehdä nykyistä eettisempiä ja läpinäkyvämpiä - Näin sanoo VTT:n johtava tutkija Raija Koivisto". Helsingin Sanomat 21.12.2018.

Vahvanen, Pekka (2018) Kone kaikkivaltias. Kuinka digitalisaatio tuhoaa kaiken meille arvokkaan. Jyväskylä: Atena. 